\title{
Response to comment on: Nauck MA, Duran S, Kim D et al (2007) A comparison of twice-daily exenatide and biphasic insulin aspart in patients with type 2 diabetes who were suboptimally controlled with sulfonylurea and metformin: a non-inferiority study. Diabetologia 50:259-267
}

\author{
M. A. Nauck • M. Trautman • R. Brodows • D. Johns • \\ J. Northrup • D. Kim
}

Received: 5 March 2007 / Accepted: 13 March 2007 / Published online: 21 April 2007

(C) Springer-Verlag 2007

To the Editor: In his letter to Diabetologia [1], P. D. Home highlights the difficulties of achieving optimal glycaemic control with insulins. While good glycaemic control was achieved with insulin (endpoint $\mathrm{HbA}_{1 \mathrm{c}}$ about $7.0 \%$ on average) in the several recently published trials identified by Home [1], other trials have reported less than optimal results, particularly for insulin mixtures [2, 3]. Subjects in the treat-to-target trial conducted by Janka et al. [3] achieved a mean endpoint $\mathrm{HbA}_{1 \mathrm{c}}$ of $7.49 \%$ with human NPH insulin 70/30. Subjects treated with biphasic insulin aspart 30 in the study conducted by Boehm et al. [2] achieved a mean $\mathrm{HbA}_{1 \mathrm{c}}$ of $8.15 \%$ at endpoint. Incidentally, this study [2] was used as a reference when designing our non-inferiority study [4].

M. A. Nauck ( $\bowtie)$

Diabetes Center,

Kirchberg 21,

37431 Bad Lauterberg im Harz, Germany

e-mail: M.Nauck@Diabeteszentrum.de

M. Trautman

Lilly Forschung,

Hamburg, Germany

R. Brodows $\cdot$ D. Johns $\cdot$ J. Northrup

Eli Lilly and Company, Lilly Corporate Center,

Indianapolis, IN, USA

D. Kim

Amylin Pharmaceuticals,

San Diego, CA, USA
Most of the treat-to-target trials demonstrate that it is possible to achieve substantial improvements in glycaemic control when insulin titration algorithms are strictly enforced and exceptional follow-up efforts (often weekly patient contacts) are made in a clinical trial setting. But when very similar approaches are used, some trials (even when conducted by the same sponsor) still achieve quite different results. For example, Rosenstock et al. [5] observed an endpoint $\mathrm{HbA}_{1 \mathrm{c}}$ of $7.8 \%$ in a meta-analysis of glargine trials, whereas an endpoint $\mathrm{HbA}_{1 \mathrm{c}}$ of $7.0 \%$ was reported in the treat-to-target trial performed by Riddle et al. [6]. How variation observed in clinical research reflects variation in clinical practice remains to be seen.

The endpoint insulin dose of $24 \mathrm{IU} /$ day reported in our current non-inferiority study [4] is lower than would be expected with a forced titration schedule. As outlined in the article, a forced titration schedule was not used [4]; rather, investigators were instructed to use fasting and postprandial glycaemic targets as a guide while seeking to achieve an optimal balance between glycaemic control and risk of hypoglycaemia as dictated by best clinical practice.

It is not entirely clear why the physicians, who had to decide on these issues according to the perceived best interest of their patients, did not suggest higher insulin doses. Our data do not allow a more detailed analysis of potential reasons. We cannot fully exclude the possibility that study physicians interested in performing this trial were biased towards avoiding hypoglycaemia rather than achieving optimal glycaemic control (as exenatide might have been presumed to have an advantage over insulin treatment in this respect). We also cannot entirely exclude the possibility that there was 
some bias in favour of the sponsor and/or its product, exenatide, despite all efforts to avoid this by placing the emphasis on glycaemic targets and the process of insulin dose titration in the protocol and in pre-study meetings. Most of the trials quoted by Home were not published when this study was designed. In future trials it should be considered whether an independent study monitoring institution might be used to accompany the insulin dose titration process and advise investigators to ensure that predefined targets are achieved.

One also must consider that background glucoselowering treatment in our study included both metformin and sulfonylureas, while in some treat-to-target trials sulfonylurea was discontinued. For example, sulfonylurea discontinuation in one arm of the study by Janka et al. [3] resulted in an increase in insulin dose of 34 IU. It should also be noted that there is substantial variation in baseline $\mathrm{HbA}_{1 \mathrm{c}}$ among the treat-to-target trials. The mean baseline $\mathrm{HbA}_{1 \mathrm{c}}$ in our exenatide-insulin comparator trials $[4,7]$ was lower than the mean baseline $\mathrm{HbA}_{1 \mathrm{c}}$ observed in many treat-to-target trials, explaining less pronounced reductions in $\mathrm{HbA}_{1 \mathrm{c}}$ while achieving a similar endpoint level. In the second exenatide trial mentioned by Home [7], exenatide and insulin glargine achieved similar glucose control, with an endpoint $\mathrm{HbA}_{1 \mathrm{c}}$ of approximately $7.1 \%$ attained in both treatment arms, which is nearly identical to the best published trial results in the studies mentioned by Home [1].

Insulin glargine and biphasic insulin mixtures are both currently recommended treatments in the escalation of glucose-lowering therapy in type 2 diabetic patients who have suboptimal metabolic control on oral glucoselowering agents. At the time, we chose biphasic insulin aspart 30 as the comparator insulin because a pharmacodynamic assessment following a test meal indicated lower serum glucose excursions with biphasic insulin aspart 30 compared with biphasic human insulin 30 and Mix25 [8]. Since improved postprandial glucose is an important glucoregulatory attribute of exenatide, we did not want to disadvantage the insulin arm in any way. More importantly, we consider our choice not to use a forced insulin titration method (rather to instruct skilled diabetologists to optimise the insulin dose) an appropriate and clinically relevant use of an insulin comparator. Since exenatide is not titrated, it can be used in a standard regimen.
We agree with Home that insulin dose optimisation is difficult. Exenatide may offer the advantage of a simple regimen without compromising glucose control as compared with insulin use outside treat-to-target clinical trials.

Duality of interest M. A. Nauck is a consultant for Eli Lilly and Company and Amylin Pharmaceuticals, has received grant support for clinical studies involving exenatide, as well as honoraria for lectures, and was invited to present the findings of the trial at congresses. M. Trautmann, R. Brodows, D. Johns and J. Northrup are employees and/or stockholders of Eli Lilly and Company. D. Kim is an employee and stockholder of Amylin Pharmaceuticals. Eli Lilly and Company and Amylin Pharmaceuticals are involved in the development of exenatide.

\section{References}

1. Home PD (2007) Comment on: Nauck MA, Duran S, Kim D et al (2007) A comparison of twice-daily exenatide and biphasic insulin aspart in patients with type 2 diabetes who were suboptimally controlled with sulfonylurea and metformin: a non-inferiority study. Diabetologia 50:259-267 DOI 10.1007/s00125-007-0653-9

2. Boehm BO, Home PD, Behrend C et al (2002) Premixed insulin aspart 30 vs premixed human insulin 30/70 twice daily: a randomized trial in type 1 and type 2 diabetic patients. Diabet Med 19:393-399

3. Janka HU, Plewe G, Riddle MC et al (2005) Comparison of basal insulin added to oral agents versus twice-daily premixed insulin as initial insulin therapy for type 2 diabetes. Diabetes Care 28:254-259

4. Nauck MA, Duran S, Kim D et al (2007) A comparison of twicedaily exenatide and biphasic insulin aspart in patients with type 2 diabetes who were suboptimally controlled with sulfonylurea and metformin: a non-inferiority study. Diabetologia 50:259-267

5. Rosenstock J, Dailey G, Massi-Benedetti M et al (2005) Reduced hypoglycemia risk with insulin glargine. Diabetes Care 28:950 955

6. Riddle MC, Rosenstock J, Gerich JE, Insulin Glargine 4002 Study Investigators (2003) The treat-to-target trial: randomized addition of glargine or human NPH insulin to oral therapy in type 2 diabetic patients. Diabetes Care 26:3080-3086

7. Heine RJ, Van Gaal L, Johns D et al (2005) Exenatide vs insulin glargine in patients with suboptimally controlled type 2 diabetes. Ann Intern Med 143:559-569

8. Hermansen K, Colombo M, Storgaard H et al (2002) Improved postprandial glycemic control with biphasic insulin aspart relative to biphasic insulin lispro and biphasic human insulin in patients with type 2 diabetes. Diabetes Care 25:883-888 